\title{
A Pilot Online Survey Assessing Risk Factors for HIV Acquisition in the Navy and Marine Corps, 2005-2010
}

\author{
Shilpa Hakre \\ Adam W. Armstrong \\ Navy Marine Corps Public Health Center \\ Robert J. O'Connell \\ Walter Reed Army Institute of Research \\ Nelson L. Michael \\ Walter Reed Army Institute of Research \\ Paul T. Scott \\ Walter Reed Army Institute of Research
}

Henry M. Jackson Foundation for the Advancement of Military Medicine

See next page for additional authors

Tell us how you used this information in this short survey.

Follow this and additional works at: https://digitalcommons.unmc.edu/coph_epidem_articles

Part of the Epidemiology Commons

\section{Recommended Citation}

Hakre, Shilpa; Armstrong, Adam W.; O'Connell, Robert J.; Michael, Nelson L.; Scott, Paul T.; and Brett-Major, David, "A Pilot Online Survey Assessing Risk Factors for HIV Acquisition in the Navy and Marine Corps, 2005-2010" (2012). Journal Articles: Epidemiology. 28.

https://digitalcommons.unmc.edu/coph_epidem_articles/28

This Article is brought to you for free and open access by the Epidemiology at DigitalCommons@UNMC. It has been accepted for inclusion in Journal Articles: Epidemiology by an authorized administrator of DigitalCommons@UNMC.For more information, please contact digitalcommons@unmc.edu. 


\section{Authors}

Shilpa Hakre, Adam W. Armstrong, Robert J. O'Connell, Nelson L. Michael, Paul T. Scott, and David BrettMajor 


\title{
A Pilot Online Survey Assessing Risk Factors for HIV Acquisition in the Navy and Marine Corps, 2005-2010
}

\author{
Shilpa Hakre, DrPH, MPH, * Adam W. Armstrong, DO, MSPH, † Robert J. O'Connell, MD, $\neq$ \\ Nelson L. Michael, MD, PhD, $\ddagger$ Paul T. Scott, MD, MPH, $\neq$ and David M. Brett-Major, MD, MPH§\|
}

\begin{abstract}
The Department of Defense policy Don't Ask, Don't Tell (DADT) ended in September, 2011. The Navy Bloodborne Infection Management Center conducted a post-DADT pilot survey of HIV seroconverters identified when the DADT policy was in effect. Sailors and Marines newly diagnosed as HIV positive from 2005 to 2010 were invited to participate in an online survey. A structured questionnaire elicited risk information about the 3-year period before HIV diagnosis. Respondents reported engaging commonly in same sex sexual activity, having concurrent partners, and poor condom use for anal sex. In this first post-DADT repeal report of self-reported behaviors, male-to-male sexual contact was a much more common mode of infection than previously reported. Several opportunities for primary prevention messaging now possible after DADT repeal are evident.
\end{abstract}

Key Words: HIV military personnel survey

(J Acquir Immune Defic Syndr 2012;61:125-130)

\section{INTRODUCTION}

Crude HIV incidence rates in the United States Navy have been declining since 2008 and currently average 30 per 100,000 persons tested although it has been stable in the United States Marine Corps, averaging 12 per 100,000 persons tested. ${ }^{1}$ In an ongoing effort to evaluate current trends in the epidemiology of HIV among its beneficiaries, the Navy

Received for publication May 4, 2012; accepted July 13, 2012.

From the *US Military HIV Research Program, Henry M. Jackson Foundation for the Advancement of Military Medicine, Bethesda, MD; †Navy Bloodborne Infection Management Center, Navy Marine Corps Public Health Center, Portsmouth, VA; IUS Military HIV Research Program, Walter Reed Army Institute of Research, Bethesda, MD; §US Military Tropical Medicine Program, Navy Medicine Professional Development Center, Bethesda, MD; and ||Department of Preventive Medicine and Biometrics, Uniformed Services University, Bethesda, MD.

Supported by US Navy Bureau of Medicine and Surgery and the Military Infectious Diseases Research Program, project MIDRP-H014010OTPPOC.

The content of this publication is the sole responsibility of the authors and does not necessarily reflect the views or policies of the Professional Development Center, Navy Marine Corps Public Health Center, the Bureau of Medicine and Surgery, the Walter Reed Army Institute of Research, Uniformed Services University, Departments of the Army, Navy or Defense, or any agency of the US Government. Mention of trade names, commercial products, or organizations does not imply endorsement by the US Government.

The authors have no conflicts of interest to disclose.

Correspondence to: Shilpa Hakre, DrPH, MPH, Epidemiology and Threat Assessment, US Military HIV Research Program, 6720-A Rockledge Drive, Suite 400, Bethesda, MD 20817 (e-mail: shakre@hivresearch.org).

Copyright (C) 2012 by Lippincott Williams \& Wilkins
Bloodborne Infection Management Center (NBIMC) initiated a quality assurance and program assessment in the last quarter of $2010 .^{2}$ NBIMC has administrative oversight of care and management of HIV-infected personnel, conducts force screening, and partners for health promotion to prevent HIV acquisition. ${ }^{3}$ The military executes a dedicated care network for those HIV infected. ${ }^{4}$

The last published report of behavioral and other risk factors for HIV seroconversion among United States Navy and United States Marine Corps personnel was data through the year 2000 from the military's HIV Natural History Study. ${ }^{5}$ As one of its program objectives, NBIMC surveyed recently identified HIV-infected Sailors and Marines to assess contemporary risk factors for HIV acquisition.

\section{METHODS}

\section{Study Design and Population}

This survey was a case series design conducted among 524 Sailors and Marines newly diagnosed as HIV positive from January 1, 2005, through August 3, 2010. From October 1, 2011, through January 16, 2012, using a standardized script and privacy protocol, a staff nurse attempted on 2 occasions to call those patients with available contact information. The Defense Manpower Data Center and NBIMC databases provided contact information for eligible Sailors and Marines. The nurse provided willing, potential participants with a link and password to an online survey. To maintain confidentiality of responses, the key code linking participants' identifying information to their survey password was deleted at the end of the survey. The Walter Reed Army Institute of Research Institutional Review Board (No 1742) determined that the overarching NBIMC quality assurance and program assessment, which encompassed the survey, constituted a public health activity. ${ }^{2}$

\section{Questionnaire}

The survey, piloted as an online instrument and tested by investigators, data management personnel, and an HIV patient who was not part of the cohort, consisted of an anonymous structured questionnaire with quantitative multiple choice and qualitative open-ended questions divided into 7 sections as follows: sociodemographic characteristics, service history, HIV care, sexually transmitted infection (STI) history, sexual risk history, and alcohol and drug use. The majority of questions pertained to the 3-year period 
before respondents' awareness of their HIV diagnosis; the period encompassed the HIV seroconversion date. Three years was chosen to capture the military's mandated 2-year force HIV screening (ie, in this case, the period between the last-negative and first-positive HIV test results) and outlying test intervals. ${ }^{2,6}$ Questions pertaining to sexual risk enquired about partner type, oral, vaginal, and anal sex, and condom use. The questionnaire ended by asking respondents for specific feedback on a few questions and general feedback on the length and content of the questionnaire.

\section{Analysis}

Demographic characteristics of the respondents were compared to the entire cohort of Sailors and Marines newly diagnosed as HIV-infected during 2005-2010. ${ }^{2}$ Self-reported geographical location of HIV acquisition was categorized into a region as follows: northeast, midwest, southern, western US and outside the continental United States. Responses to openended questions were grouped into data-driven themes, and frequencies by theme were summarized. Tests of significance (Pearson $\chi^{2}$, Fisher exact test, $p \leq 0.05,2$-sided) compared the frequencies of participants to the entire cohort. The questionnaire was administered as a web-based survey through Qualtrics (Provo, UT). Data management and analysis were conducted using Statistical Analysis Software version 9.2 (SAS Cary, NC).

\section{RESULTS}

\section{Demographic Profile}

Among 250 of the 524 Sailors and Marines for whom contact information was available and who were called, 64 $(26 \%)$ participated in the online survey; most $(89 \%)$ were Sailors (Table 1). Respondents indicated that the survey took an average of half an hour to complete. At the time of HIV notification, respondents averaged 29.1 years (median: 28.0, range: $19.0-45.0)$ in age, were all men, predominantly junior enlisted (E1-E5, 55\%), never married (61\%), and educated ( $81 \%$ had attended college or earned a degree) and differed significantly from the cohort of $524(P<0.0001)$ in rank, racial makeup, and education but not by age or service $(P \geq$ $0.05){ }^{2}$ They included more junior enlisted (E1-E5: $55 \%$ vs. $43 \%$ cohort), and those educated ( $>$ high school: $81 \%$ vs. cohort 7\%). Respondents had served a median of 6.0 years (range: $0.0-25.0$ ) at the time of HIV notification.

\section{Risk Profile}

Respondents reported homosexual partner (84\%) and sex with nonservice members $(55 \%)$ as the most common risk for exposure to HIV (Table 1). In the seroconversion period, more than half $(55 \%)$ of respondents reported having sex with only men (median number of partners: 5, range: 0-250), whereas $30 \%$ reported having sex with both men and women. Almost half $(48 \%)$ of respondents had concurrent relationships with different partners in the seroconversion period. A majority $(68 \%)$ reported that their concurrent partners were only men, whereas $19 \%$ reported dating both men and women at the same time. Also, a majority of respondents reported never or inconsistently using condoms for anal sex $(70 \%)$ or for oral sex (84\%, Fig. 1). One-third (20/60, 33\%) of respondents decided whether to use condoms or not based on how well they knew or trusted their sex partner; $12 \%$ (7/60) based their decision on their partner's HIV status. Reasons for never using condoms $(n=31)$ included oral sex was not risky $(29 \%)$, trusted or knew a partner $(19 \%)$, personal preference $(13 \%)$, poor judgment or alcohol use $(10 \%)$, and knew partner's HIV status $(6 \%)$.

Sailors and Marines commonly reported meeting new, casual, or temporary partners at a bar or club $(75 \%)$, followed by the internet $(67 \%) ; 42 \%$ reported that new, casual, or temporary partners were only non-service members whereas $47 \%$ reported these partners were both service and nonservice members (Table 1). Nearly half $(25 / 63,39 \%)$ of respondents participated in group sex. Fifty-six percent had a tattoo. Almost a third $(18 / 63,29 \%)$ reported being forced to have sex; $88 \%$ of these before adulthood.

\section{Sexually Transmitted Infections and Other History}

In the seroconversion period, respondents most commonly reported being tested for gonorrhea (45\%) followed by syphilis $(41 \%) ; 87 \%$ of respondents tested for gonorrhea also reported having a diagnosis of gonorrhea while $67 \%$ of respondents tested for syphilis reported having a syphilis diagnosis. One in five respondents $(20 \%)$ reported ever seeking care for a STI in the civilian community. A majority $(84 \%)$ of the respondents were circumcised.

\section{HIV Testing, Care, and Infection}

Half $(51 \%)$ of the respondents reported that their positive HIV test was obtained for service-related reasons such as testing for interval force-wide, pre-, and postdeployment, or permanent change of duty station (PCS), while $37 \%$ had requested a HIV test (Table 1). Three-quarters (78\%) reported being surprised by the initial positive test results. A majority $(30 / 44,68 \%)$ of respondents reported being notified of their HIV infection status during the same year when they believed that they became infected.

\section{Alcohol or Substance Use}

Almost two-thirds (62\%) of respondents occasionally or typically drank alcohol before sex in the seroconversion period. In general, $33 \%$ said alcohol had some or a great deal of influence in taking sexual risks. Only $8 \%$ of respondents reported using substances in the seroconversion period; $80 \%$ of this group reported that it had a great deal of influence on taking greater sexual risks. Reported substances ranged from illicit drugs to inhalants. 
TABLE 1. Demographic and Risk Features of 64 Sailors and Marines Newly Identified as HIV Infected, 2005-2010

\begin{tabular}{|c|c|c|}
\hline Characteristic* & Category & All Respondents, $n=64$ \\
\hline \multirow[t]{2}{*}{ Service } & Marine & $7(11)$ \\
\hline & Navy & $57(89)$ \\
\hline \multirow[t]{3}{*}{ Rank } & E1-E5 & $35(55)$ \\
\hline & E6-E9 & $23(36)$ \\
\hline & Officer & $6(9)$ \\
\hline Age $\dagger$ & Median years (range) & $28(19-45)$ \\
\hline \multirow[t]{2}{*}{ Marital status } & Single, never married & $39(61)$ \\
\hline & Married/previously married & $25(39)$ \\
\hline \multirow[t]{4}{*}{ Race/ethnicity } & Black (not Hispanic) & $27(42)$ \\
\hline & White (not Hispanic) & $23(36)$ \\
\hline & Hispanic & $11(17)$ \\
\hline & Other & $3(5)$ \\
\hline \multirow[t]{4}{*}{ Education } & Graduate or professional degree & $5(8)$ \\
\hline & College, or some College & $39(61)$ \\
\hline & Undergraduate degree & $8(13)$ \\
\hline & High school, or some High school & $12(19)$ \\
\hline Length of service $\dagger$ & Median years (range) & $6(<1-25)$ \\
\hline History of assignment changes $\dagger$ & Median number (range) & $3(0-9)$ \\
\hline History of deployments $\dagger$ & Median number (range) & $2(0-10)$ \\
\hline \multirow[t]{3}{*}{ Calendar year of notification } & $2005-2006$ & $20(33)$ \\
\hline & $2007-2008$ & $26(43)$ \\
\hline & 2009-2010 & $15(24)$ \\
\hline \multirow[t]{4}{*}{ Reason for testing $\ddagger$} & Command initiated & $7(12)$ \\
\hline & Force testing per DoD policy & $22(39)$ \\
\hline & Requested by participant & $21(37)$ \\
\hline & Tested because of illness (clinical indication, sick) & $6(11)$ \\
\hline Sought civilian HIV testing & Ever & $15(26)$ \\
\hline \multirow[t]{4}{*}{ Notifier of positive HIV result } & Commander & $34(60)$ \\
\hline & Physician & $11(19)$ \\
\hline & Public Health Nurse & $3(5)$ \\
\hline & Other & $9(16)$ \\
\hline Interval, HIV acquisition§ to notification & Median years (range) & $0(0-4)$ \\
\hline \multirow[t]{5}{*}{ Geographical region, HIV acquisition§ } & South & $26(46)$ \\
\hline & West & $17(30)$ \\
\hline & Midwest & $3(5)$ \\
\hline & Northeast & $3(5)$ \\
\hline & OCONUS & $8(14)$ \\
\hline \multirow[t]{4}{*}{ STI, diagnosed, $\mathrm{n}=63 \boldsymbol{\Phi} \|$} & Gonorrhea & $15(23)$ \\
\hline & Chlamydia & $5(8)$ \\
\hline & Syphilis & $12(19)$ \\
\hline & Condyloma & $7(11)$ \\
\hline \multirow[t]{5}{*}{ Self-reported risk group for HIV exposure\# } & Homosexual partner & $54(84)$ \\
\hline & Sexual contact, nonservice members & $35(55)$ \\
\hline & Sexual contact, other service members & $15(23)$ \\
\hline & Heterosexual partner & $9(14)$ \\
\hline & Sexual contact, known HIV-positive person & $3(5)$ \\
\hline \multirow[t]{3}{*}{ Sex (oral, vaginal, anal) } & Both men and women (19\%), median (range) & $7(0-250)$ \\
\hline & Only men $(55 \%)$, median (range) & $5(0-250)$ \\
\hline & Only women $(8 \%)$, median (range) & $0(0-50)$ \\
\hline Sex with concurrent partners $\uparrow$ & Indicated & $31(48)$ \\
\hline \multirow[t]{3}{*}{ Gender, concurrent partners, $\| \mathrm{n}=31$} & Both men and women & $6(19)$ \\
\hline & Only men & $21(68)$ \\
\hline & Only women & $4(13)$ \\
\hline
\end{tabular}


TABLE 1. (Continued) Demographic and Risk Features of 64 Sailors and Marines Newly Identified as HIV Infected, 2005-2010

\begin{tabular}{|c|c|c|}
\hline Characteristic* & Category & All Respondents, $n=64$ \\
\hline \multirow[t]{6}{*}{ Frequency of sex, concurrent partners, $\| \mathrm{n}=31$} & 1 time & $1(3)$ \\
\hline & $2-3$ times & $11(11)$ \\
\hline & More than 3 times, but not regularly & $6(19)$ \\
\hline & Regularly (monthly, $\geq 2$ different people) & $5(16)$ \\
\hline & Regularly (weekly, $\geq 2$ different people) & $6(19)$ \\
\hline & Don’t know/Don’t remember & $2(6)$ \\
\hline \multirow[t]{7}{*}{ Meeting places, new/casual/temporary partners } & Work & $18(28)$ \\
\hline & $\mathrm{Bar} / \mathrm{Club}$ & $48(75)$ \\
\hline & Restaurant & $5(8)$ \\
\hline & Internet & $43(67)$ \\
\hline & On vacation & $12(19)$ \\
\hline & Temporary duty & $10(16)$ \\
\hline & Other & $2(3)$ \\
\hline \multirow[t]{3}{*}{ Partner type, new/casual/temporary $\Phi^{* *}$} & Nonservice members & $27(42)$ \\
\hline & Service members & $2(3)$ \\
\hline & Service members and nonservice members & $30(47)$ \\
\hline Traded sex for money/goods/favors & Ever & $6(9)$ \\
\hline \multirow[t]{8}{*}{ Preventive information best received } & Peer education & $34(53)$ \\
\hline & Physician or other health professional & $33(52)$ \\
\hline & General military training & $22(34)$ \\
\hline & Online training & $18(28)$ \\
\hline & Email alert & $5(8)$ \\
\hline & Telephone text messages & $4(6)$ \\
\hline & Music (such as a rap song) & $3(5)$ \\
\hline & Other & $15(23)$ \\
\hline
\end{tabular}

n (\%) unless otherwise noted.

*At first positive test.

$\dagger$ At/until notification.

tScreening for blood donation (2\%).

$\S$ Self-reported date and location of exposure to HIV

'SSeroconversion period (i.e. three years before respondents' awareness of their HIV diagnosis).

||Diagnosis of urethritis (3\%).

\#Data less than 5\% is not shown and included sexual contact with a commercial sex worker outside U.S.(3\%), sexual contact with a commercial sex worker in United States ( $2 \%)$, and transfusion $(2 \%)$.

**No new/casual/temporary partners $(8 \%)$

DoD, Department of Defense; OCONUS, outside the continental United States.

\section{Mental Health}

Among respondents, $19 \%$ felt a life event contributed to their risk for HIV. Life events reported as contributing factors were death of a loved one $(5 \%)$, notification of or impending deployment ( $9 \%)$, notification of or impending mobilization from reserves (2\%), impending accession into the military $(2 / 63,3 \%)$, development of a chronic disease $(3 \%)$, changes in marital $(3 / 63$, $5 \%)$ or financial status $(3 / 63,5 \%)$, and disciplinary action $(3 \%)$.

\section{Prevention}

Respondents felt preventive information would be best received by peer education $(54 \%)$ or from a physician or other health professional (Table 1).

\section{DISCUSSION}

The policy Don't Ask, Don't Tell (DADT) in effect since $1994^{7}$ ended as of September 20, 2011, leading to a phased end to the ban on openly homosexual individuals serving in the US Armed Forces. ${ }^{8}$ NBIMC conducted a postDADT pilot survey of HIV-infected Sailors and Marines newly-identified when the DADT policy was in effect. Respondents reported engaging commonly in several highrisk behaviors: sex with a homosexual partner/sex with men with numbers of partners in the seroconversion period ranging from none to 250 men, concurrent partners, unsafe oral and anal sex.

Among males aged 13 years or older, men who have sex with men (MSM) accounted for $77 \%$ of HIV diagnosis in the United States from 2007 to $2010 . .^{9}$ In previous studies in the military, $59 \%$ of male HIV seroconverters reported having sex with only men or with both sexes. ${ }^{5,10}$ Although the population NBIMC surveyed was restricted to Sailors and Marines, and the respondents, who constituted a fourth of those contacted, differed in several demographic aspects from the general 2005-2010 cohort of HIV-infected Sailors and Marines, the considerably higher $84 \%$ reported in this survey 


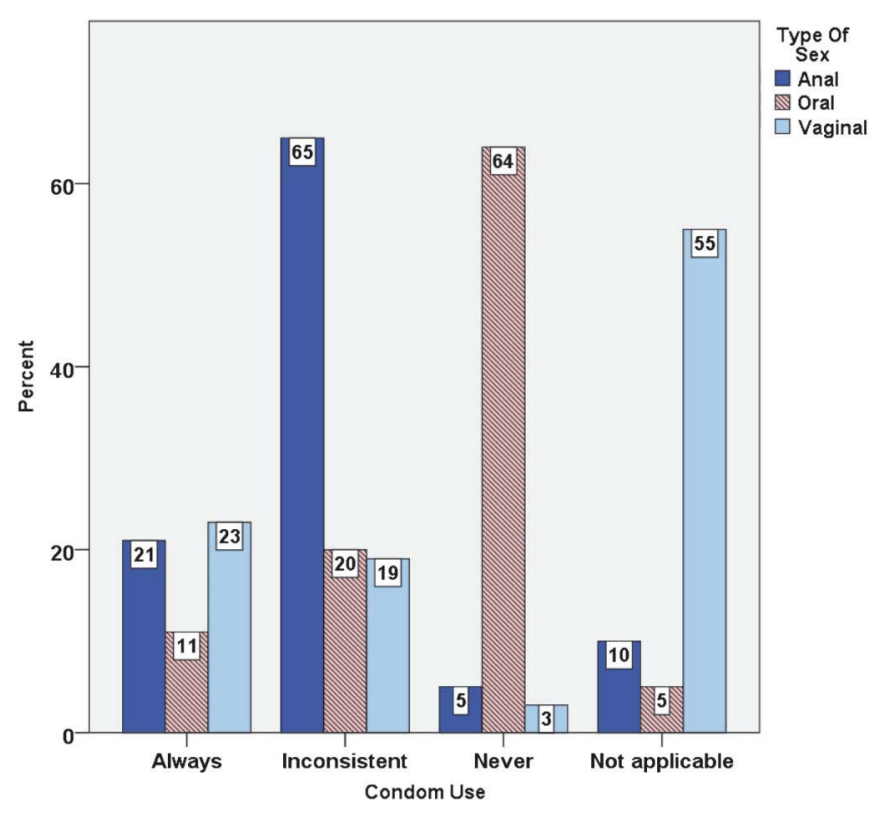

FIGURE 1. Frequency of condom use reported by 64 Sailors and Marines newly-identified as HIV-infected, 2005-2010*. *Sixty-three of 64 Sailors and Marines responded to questions about condom use for oral and anal sex.

may reflect liberalized responses due to DADT repeal effects. Almost one-fourth of respondents had sought civilian health care for STIs. Military personnel have been reported to seek care in the civilian community for fear of being discharged if their sexual orientation is revealed whilst in care at military health care facilities. ${ }^{11,12}$ In one study, 9\% of a gay health clinic's clientele were Sailors and men who have sex with men; a majority sought paid care at the clinic after high risk sexual exposure despite access to free health care in the US military. ${ }^{12}$ This survey's 1 in 5 rate of seeking civilian STI care outside the military health system is consistent with these concerns.

More than three-quarters of respondents were surprised at their HIV test result. Self-reported condom use was poor. The most common reasons revealed for this were how well a partner was known or trusted and a partner's HIV status. These results indicate Sailors and Marines underestimated their individual risk of HIV acquisition, revealing persistent opportunities for condom-related sexual health prevention messaging despite robust efforts through the Sexual Health and Responsibility Program. ${ }^{13}$ Prior studies in civilian populations found that unprotected anal sex was more likely with partners of longer acquaintance and with partners whose HIV serostatus was perceived to have been known. ${ }^{14-16}$ HIV risk reduction strategies discussed with partners of longer acquaintance may have been broken by their partners. ${ }^{17,18}$ Crosby and Mettey ${ }^{17}$ found that nearly one quarter of men at a southwestern United States sex resort who reported being HIV negative had not been tested in the previous year. The relationship between length of acquaintance, unprotected sex, and disclosure of HIV serostatus among service members and their varied military and civilian partners is not well understood. An understanding of these relationships may help to promote safer sex. Respondents indicated that peer messaging would be important to this effort.

In summary, in an online survey of HIV-infected Sailors and Marines, MSM exposure dominated the HIV risk acquisition profile similar to the national HIV epidemic and contrary to previous estimates of its role in HIV risk in the military. Although survey findings may not be generalizable to the 2005-2010 cohort and self-reported behaviors may be subject to recall bias, participants commonly reported same sex sexual activity, concurrent and multiple partners, poor condom use, and surprise at receiving HIV-positive results. DADT repeal may afford opportunities for facilitating necessary primary HIV prevention strategies such as those targeting condom use and newer social outlets such as Internet networking. Continued work may be needed to ensure detection of and action in response to indicators for secondary prevention such as STI.

\section{ACKNOWLEDGMENTS}

The authors thank all survey respondents for their honesty and generosity in participating in the survey. The authors are grateful to Ms Rebecca Ringwood for her untiring efforts in contacting, recruiting, and distributing the survey and Dr Judith Harbertson (US Military HIV Research Program, Navy Health Research Center) and $\mathrm{Mr}$ Bob MacDonald (Sexual Health and Responsibility Program, Navy and Marine Corps Public Health Center) for their suggestions in reviewing the questionnaire. The authors appreciate the efforts of Mr Greg Pfeiffer, Mr Mark Milazzo, and Mr Jared Stull (Data Coordinating and Analysis Center, MHRP) in building the survey in Qualtrics. Dr Neal Naito, formerly of the Navy's Bureau of Medicine and Surgery, provided substantive guidance and encouragement throughout the early phases of this study.

\section{REFERENCES}

1. Armed Forces Health Surveillance Center. Updates: routine screening for antibodies to HIV-1, civilian applicants for U.S. military service and U.S. Armed Forces, active and reserve components. MSMR. 2011; 18:15-22.

2. Brett-Major DM, Hakre S, Naito NA, et al. Epidemiology of contemporary seroincident HIV infection in the navy and marine corps Mil Med. 2012; In press.

3. Navy and Marine Corps Public Health Center. Navy bloodborne infection management center (NBIMC). 2012; Available at: http: //www.nmcphc.med.navy.mil/Field_activities/HIV_Program/index. aspx. Accessed February 16, 2012.

4. Crum NF, Grillo M, Wallace MR. HIV care in the U.S. navy: a multidisciplinary approach. Mil Med. 2005;170:1019-1025.

5. Brodine SK, Starkey MJ, Shaffer RA, et al. Diverse HIV-1 subtypes and clinical, laboratory and behavioral factors in a recently infected US military cohort. AIDS. 2003; 17:2521-2527.

6. Department of Defense. Department of Defense Instruction. Subject: Human Immunodeficiency Virus. 2006; 6485.01(October 17, 2006). Available at: http://www.dtic.mil/whs/directives/corres/pdf/648501p.pdf. Accessed August 13, 2012.

7. U.S. Department of Defense, Office of the Assistant Secretary of Defense (Personnel and Readiness), Report to the Secretary of Defense, Review of the Effectiveness of the Application and Enforcement of the Department's Policy on Homosexual Conduct in the Military, April 1998: 3. Available at: http://www.dod.mil/pubs/rpt040798.html. Accessed August 13, 2012. 
8. Under Secretary of Defense. Memorandum. Subject: Repeal of "Don't Ask, Don't Tell". Washinton, DC: Department of Defense; 2011.

9. Centers for Disease Control and Prevention. HIV Surveillance Report, 2010; vol. 22. Available at: http://www.cdc.gov/hiv/topics/surveillance/ resources/reports/. Accessed March 6, 2012.

10. Brodine SK, Shaffer RA, Starkey MJ, et al. Drug resistance patterns, genetic subtypes, clinical features, and risk factors in military personnel with HIV-1 seroconversion. Ann Intern Med.1999;131: 502-506.

11. Katz KA. Health hazards of “don't ask, don't tell”. N Engl J Med. 2010; 363:2380-2381

12. Smith DM. Active duty military personnel presenting for care at a Gay Men's Health Clinic. J Homosex. 2008;54:277-279.

13. Navy and Marine Corps Public Health Center. Sexual health \& responsibility program (SHARP). 2012; Available at:http://www-nehc.med.navy.mil/ Healthy_Living/Sexual_Health/sharp_main.aspx. Accessed March 21, 2012.
14. van den Boom W, Stolte I, Sandfort T, et al. Serosorting and sexual risk behaviour according to different casual partnership types among MSM: the study of one-night stands and sex buddies. AIDS Care. 2012;24:167-173.

15. Prestage G, Jin F, Grulich A, et al. Gay men are less likely to use condoms with casual sex partners they know 'well'. AIDS Behav. 2011;16:664-668.

16. Rouwenhorst E, Mallitt KA, Prestage G. Gay men's use of condoms with casual partners depends on the extent of their prior acquaintance. AIDS Behav. 2011;16(6):1589-1596.

17. Crosby R, Mettey A. A descriptive analysis of HIV risk behavior among men having sex with men attending a large sex resort. J Acquir Immune Defic Syndr. 2004:37:1496-1499.

18. Guzman R, Colfax GN, Wheeler S, et al. Negotiated safety relationships and sexual behavior among a diverse sample of HIV-negative men who have sex with men. J Acquir Immune Defic Syndr. 2005; $38: 82-86$. 